\title{
Remoção de matéria orgânica e sólidos suspensos por nova configuração de biofiltro aeróbio submerso no pós-tratamento de efluente de reator UASB
}

\section{Removal of organic matter and suspended solids by a new configuration of biological aerated filter in the post-treatment of UASB reactor effluent}

\author{
Saulo Varela Della Giustina \\ M.Sc. em Recursos Hídricos e Saneamento Ambiental pelo Instituto de Pesquisas Hidráulicas da Universidade Federal do Rio Grande do Sul (UFRGS). \\ Luis Alcides Schiavo Miranda \\ Pós-Doutor pelo Instituto de Pesquisas Hidráulicas da UFRGS. Professor Assistente Il do Programa de Pós-graduação em Engenharia Civil da Universidade \\ do Vale do Rio dos Sinos (UNISINOS).

\section{Luiz Olinto Monteggia} \\ Ph.D. em Engenharia de Meio Ambiente pela Universidade Newcastle (UK). Professor Adjunto pelo Instituto de Pesquisas Hidráulicas da UFRGS.
}

\begin{abstract}
Resumo
O pós-tratamento de efluentes de reatores anaeróbios é um processo necessário para o atendimento dos padrões de emissão. Os resultados aqui apresentados mostram a viabilidade de uso de uma nova configuração de biofiltro aeróbio submerso (BAS) no pós-tratamento desses efluentes. Os BAS multiestágio apresentam uma câmara anaeróbia $(V=12,6 \mathrm{~L})$, seguido de uma câmara aeróbia $(\mathrm{V}=30 \mathrm{~L})$ e uma câmara anóxica $(\mathrm{V}=26,4 \mathrm{~L})$, todas em série $(\mathrm{V}$ total=70L). Neste estudo, foi analisada a remoção de sólidos suspensos (SS), DQO e $\mathrm{DBO}_{5}$. Foram utilizados três BAS multi-estágio preenchidos com três diferentes materiais-suporte: tampas e gargalos PET $\left(165 \mathrm{~m}^{2} / \mathrm{m}^{3}\right)$, pedra britada $\mathrm{n} .4\left(50 \mathrm{~m}^{2} / \mathrm{m}^{3}\right)$ e anéis Pall $1,5^{\prime \prime}\left(135 \mathrm{~m}^{2} / \mathrm{m}^{3}\right)$. Os reatores foram operados com valores de tempos de detenção hidráulicas (TDH) de 4,1, 8,2 e 12,3 horas, e três taxas de aplicação superficial (TAS) (21, 12 e 8m³/m².d). A associação dos reatores UASB+BAS possibilitou remoções de DQO total superiores a 90\% para os BAS 1 e 3, e 85\% para o BAS 2, sendo independente do TDH aplicado. A remoção de SS foi maior no BAS contendo anéis Pall, provavelmente devido ao maior índice de vazios desse material.
\end{abstract}

Palavras-chave: Pós-tratamento de efluente de reator UASB; BAS multi-estágio; remoção de DQO; remoção de SS.

\begin{abstract}
The post-treatment of effluents from anaerobic reactors is normally a mandatory step to meet the emission standards. The results presented here show the feasibility of using a new configuration of biological aerated filter (BAF) in the post-treatment of UASB reactors. The multi-stage BAF presents an anaerobic chamber $(\mathrm{V}=12.6 \mathrm{~L})$, followed by an aerobic chamber $(\mathrm{V}=3 \mathrm{~L} \mathrm{~L})$ and an anoxic chamber $(\mathrm{V}=26.4 \mathrm{~L})$, all in series (total $\mathrm{V}=70 \mathrm{~L})$. This study examined the removal of suspended solids (SS), $\mathrm{COD}$ and $\mathrm{BOD}_{5}$. Three multi-stage BAF filled with three different packing materials were used: lids and bottlenecks of PET bottles $\left(165 \mathrm{~m}^{2} / \mathrm{m}^{3}\right)$, gravel n. $4\left(50 \mathrm{~m}^{2} / \mathrm{m}^{3}\right)$ and Pall rings $1.5^{\prime \prime}\left(135 \mathrm{~m}^{2} / \mathrm{m}^{3}\right)$. The reactors were operated with the values of hydraulic detention time (HDT) of $4.1,8.2$ and 12.3 hours, and three superficial application rates $\left(21,12\right.$ and $8 \mathrm{~m}^{3} / \mathrm{m}^{2}$.d). COD removal efficiencies of $90 \%$ for BAF 1 and 3 , and $85 \%$ for BAF 2 were obtained, being the removal independent of the HDT applied to BAF. The removal of SS was higher in BAF containing Pall rings, probably due to the higher voidage of this material.
\end{abstract}

Keywords: Post-treatment of UASB reactor; BAS multi-stage; removal of COD; SS removal.

Endereço: Saulo Varela Della Giustina - Avenida Bento Gonçalves, 9.500 - Agronomia - Porto Alegre (RS) - CEP: 91501-970, Brasil - Tel: (51) 3308-6660 -

Recebido: 13/01/10 - Aceito: 24/09/10 - Reg. ABES: 00610 


\section{Introdução}

O reator UASB é uma alternativa de viabilidade comprovada no tratamento de efluentes domésticos, sendo plenamente aplicável em regiões de clima quente e de interesse econômico para países em desenvolvimento (VIEIRA, 1988). No entanto, o efluente do reator UASB normalmente não alcança os padrões de lançamento exigidos pela legislação ambiental, fazendo-se necessária a implantação de uma etapa de tratamento complementar (GONÇALVES et al., 1997).

Os processos de crescimento aderido têm provado sua viabilidade em termos de tratamento a nível secundário de águas residuárias, tanto de origem industrial como doméstica. Dentre as modalidades existentes, os biofiltros aerados submersos (BAS) destacam-se pela pequena necessidade de área em planta e pelas cargas orgânicas aplicáveis muito superiores aos processos biológicos convencionais, alcançando elevada eficiência de remoção de compostos orgânicos e sólidos suspensos (SS) (AISSE \& SOBRINHO, 2000; GÁLVEZ et al., 2003).

Gonçalves et al. (1997) citam os BAS como uma modalidade aeróbia de crescimento aderido em franco desenvolvimento, podendo constituir-se em uma excelente opção para o pós-tratamento de reatores UASB, devido à sua capacidade de remover os compostos solúveis e de reter as partículas em suspensão do efluente anaeróbio. A baixa produção de lodo e o reduzido consumo de energia no estágio secundário de tratamento, aliados às qualidades já mencionadas do reator UASB, são vantagens do sistema UASB+BAS.

A seleção do material-suporte é uma etapa crítica do projeto e da operação de um sistema envolvendo BAS, pois deve permitir a fixação dos micro-organismos e reter fisicamente os SS presentes no efluente.

Diversos materiais, que podem ser classificados basicamente em minerais ou sintéticos, têm sido empregados para esse fim. Dentre os materiais minerais, os mais largamente empregados são os grãos de argila calcinada ou xisto expandido, da família dos silicatos filitosos, empregados devido à grande quantidade de pesquisas realizadas a partir da década de 1980, quando foram realizadas as primeiras aplicações em escala real. Outros tipos de materiais-suporte minerais, como os arenosos, pozolana e carvão ativado, são utilizados mais raramente (CHERNICHARO, 1997).

Segundo Moore et al. (2001), as dimensões do material de empacotamento ditam, geralmente, a carga máxima que pode ser aplicada ao biofiltro. Isso pode ser justificado pelo fato de que materiais com dimensões menores apresentam uma maior área específica disponível para o desenvolvimento do biofilme, consequentemente minimizando o volume necessário de reator para o tratamento.

Segundo Gonçalves et al. (2001), a forma dos grãos não influencia significativamente no desempenho do processo, sendo mais importantes as características de superfície, como a área específica e a rugosidade, que facilitam a adesão da biomassa.

He et al. (2006) estudaram o uso de zeólita natural e argila expandida como material- suporte de BAS tratando efluente doméstico, quando sob o efeito de baixas temperaturas e de choques de carga de nitrogênio amoniacal. Ambos os materiais possibilitaram elevadas eficiências de remoção de DQO, SS e nitrogênio amoniacal (>85\% para DQO e $>93 \%$ para $\mathrm{NH}_{3}-\mathrm{N}$ ). Por meio do estudo da biomassa heterotrófica e nitrificante, verificou-se, no entanto, que o melhor material-suporte no experimento em questão foi a zeólita, dada sua capacidade de trocar íons e, assim, maior capacidade de nitrificação, que possibilita a resistência a choques de carga.

Outros materiais alternativos, como conchas de ostras (LIU et al., 2010), esferas plásticas (LIU et al., 2010; XIE et al.; 2010), peças cerâmicas e rocha carbonatada (QIU et al., 2010), também foram avaliados no tratamento de efluentes domésticos em BAS, sendo relatados desempenhos satisfatórios (\%Ef. DQO>85\%; \%Ef. $\mathrm{NH}_{3}-\mathrm{N}>90 \%$ ) para todos os materiais. Em particular, materiais-suporte com a capacidade de suprir alcalinidade para o meio apresentaram vantagens em processos nos quais há a presença de valores de $\mathrm{pH}$ instáveis e/ou efluentes com elevadas cargas de nitrogênio amoniacal.

No presente estudo são apresentados os resultados obtidos no tratamento de efluente sanitário utilizando reator UASB e BAS multiestágio associados, operados em condições de carregamento orgânico e hidráulico, com o objetivo de avaliar a eficiência de remoção de matéria orgânica e SS por meio da associação de câmara anaeróbia, aeróbia e anóxica em série. Também foi dada ênfase à avaliação de diferentes materiais para o empacotamento dos biofiltros, em termos de custos e características básicas, como superfície específica, índice de vazios e peso.

\section{Metodologia}

O experimento foi realizado na Estação Experimental da Universidade Federal do Rio Grande do Sul (UFRGS), em área contígua à Estação de Tratamento de Efluentes (ETE) São João/Navegantes do Departamento Municipal de Água e Efluente (DMAE) em Porto Alegre (RS). Para o presente estudo, foram construídas três unidades em escala piloto de BAS multi-estágios e o reator UASB com volume útil de $18,3 \mathrm{~m}^{3}$.

O efluente doméstico foi captado após o pré-tratamento (grade e caixa de areia) no canal de alimentação do sistema de lodos ativados que compõe a ETE São João/Navegantes, sendo conduzido a um tanque de recepção para remoção adicional de sólidos grosseiros por peneiramento. Desse tanque, o efluente bruto foi recalcado para o reator UASB e, após, direcionado para cada BAS por bombeamento.

Os BAS foram construídos em tubo de acrílico de $4 \mathrm{~m}$ de altura e $0,15 \mathrm{~m}$ de diâmetro. Foram testados três diferentes materiais-suporte, nomeadamente: tampas e gargalos de garrafa PET $\left(165 \mathrm{~m}^{2} / \mathrm{m}^{3}\right)$, pedra britada n. ${ }^{\circ} 4\left(50 \mathrm{~m}^{2} / \mathrm{m}^{3}\right)$ e anéis Pall $\left(135 \mathrm{~m}^{2} / \mathrm{m}^{3}\right)$, sendo denominados BAS 1, 2 e 3, respectivamente. Cada BAS possui uma câmara anaeróbia, aeróbia e anóxica em série, com volumes de 13,6L, 30L e 26,4L, respectivamente. A Tabela 1 apresenta as características dos materiais 
Tabela 1 - Características dos materiais empregados como material-suporte para preenchimento de cada BAS

\begin{tabular}{lccc} 
Material-suporte & BAS 1 & BAS 2 & BAS 3 \\
\cline { 2 - 4 } & Tampas e gargalos PET & Brita $\mathrm{n}^{\circ} 4$ & Anel Pall 1,5" \\
Massa específica $\left(\mathrm{kg} / \mathrm{m}^{3}\right)$ & 200 & 1650 & 71 \\
Superfície específica $\left(\mathrm{m}^{2} / \mathrm{m}^{3}\right)$ & 165 & 50 & 135 \\
Índice Vazios $(\%)$ & 75 & 50 & 95 \\
Área total $\left(\mathrm{m}^{2}\right)$ & 9,17 & 2,8 & 11,2
\end{tabular}

BAS: biofiltro aerado submerso.

empregados e a área resultante do preenchimento de cada BAS, enquanto que a Figura 1 apresenta um esquema do BAS.

O período experimental compreendeu 310 dias, durante os quais foram avaliados três tempos de detenção hidráulicas (TDHs): 4,1, 8,2 e 12,3 horas, correspondendo a TDHs de 1,75, 3,5 e 5,75 horas nas câmaras aeróbias de cada BAS, conforme Tabela 2. O TDH do reator UASB foi mantido em 12 horas durante o experimento.

O aumento das cargas orgânicas volumétricas (COV) aplicadas aos BAS foi obtido por meio do aumento da vazão.

As amostras foram analisadas semanalmente, sendo avaliados os seguintes parâmetros: $\mathrm{pH}$, sólidos totais (ST), sólidos suspensos totais (SS), sólidos dissolvidos totais (SDT), sólidos fixos totais (SFT), sólidos voláteis totais (SVT), DQO total, DQO solúvel, DQO decantada, conforme American Public Health Association (APHA), American Water Works Association (AWWA), Water Environment Federation (WEF) (2005). Para a análise da DQO decantada, procedeu-se à sedimentação das amostras por 60 minutos em proveta graduada. As amostras foram coletadas ao final da câmara aeróbia e também na saída da câmara anóxica (saída do BAS). Os BAS não foram expostos a retrolavagens em nenhum momento do período experimental.

\section{Resultados e discussão}

\section{DQO total}

A Figura 2 apresenta os dados de DQO total, solúvel e decantada para as etapas 1, 2 e 3, bem como as eficiências totais obtidas para os sistemas experimentais. Nos gráficos, pode-se verificar que o reator UASB apresentou boas eficiências de remoção de DQO total ao longo do período experimental, com valor médio de 75,2\%.

Esse desempenho foi associado às características do efluente bruto, o qual apresentou uma parcela representativa de sua DQO na forma particulada, conforme a Tabela 3. Verifica-se, para a $1^{\text {a }}$ etapa, por exemplo, que a concentração de DQO particulada corresponde a $82 \%$ da DQO total $\left(722 \mathrm{mgO}_{2} \cdot \mathrm{L}^{-1}-168 \mathrm{mgO}_{2} \cdot \mathrm{L}^{-1}\right)$. Esse comportamento também foi verificado nas demais etapas do estudo.

Os resultados de remoção de DQO total nos BAS frente ao reator UASB para a primeira etapa (Tabela 4) foram afetados diretamente por elevadas perdas de sólidos na saída da câmara anóxica, resultando em concentrações efluentes superiores às afluentes para os BAS.
Tabela 2 - Regimes operacionais empregados nos BAS

\begin{tabular}{|c|c|c|c|c|c|}
\hline \multirow{2}{*}{ Etapa } & \multicolumn{4}{|c|}{ TDH (h) } & \multirow{2}{*}{$\begin{array}{l}\text { Vazão } \\
\left(\text { L.h.' }{ }^{-1}\right)\end{array}$} \\
\hline & Anaeróbia & Aeróbia & Anóxica & Total & \\
\hline 1 & 0,77 & 1,75 & 1,5 & 4,1 & 17,1 \\
\hline 2 & 1,54 & 3,5 & 3,1 & 8,2 & 8,6 \\
\hline 3 & 2,31 & 5,25 & 4,6 & 12,3 & 5,7 \\
\hline
\end{tabular}

TDH: tempo de detenção hidráulica.

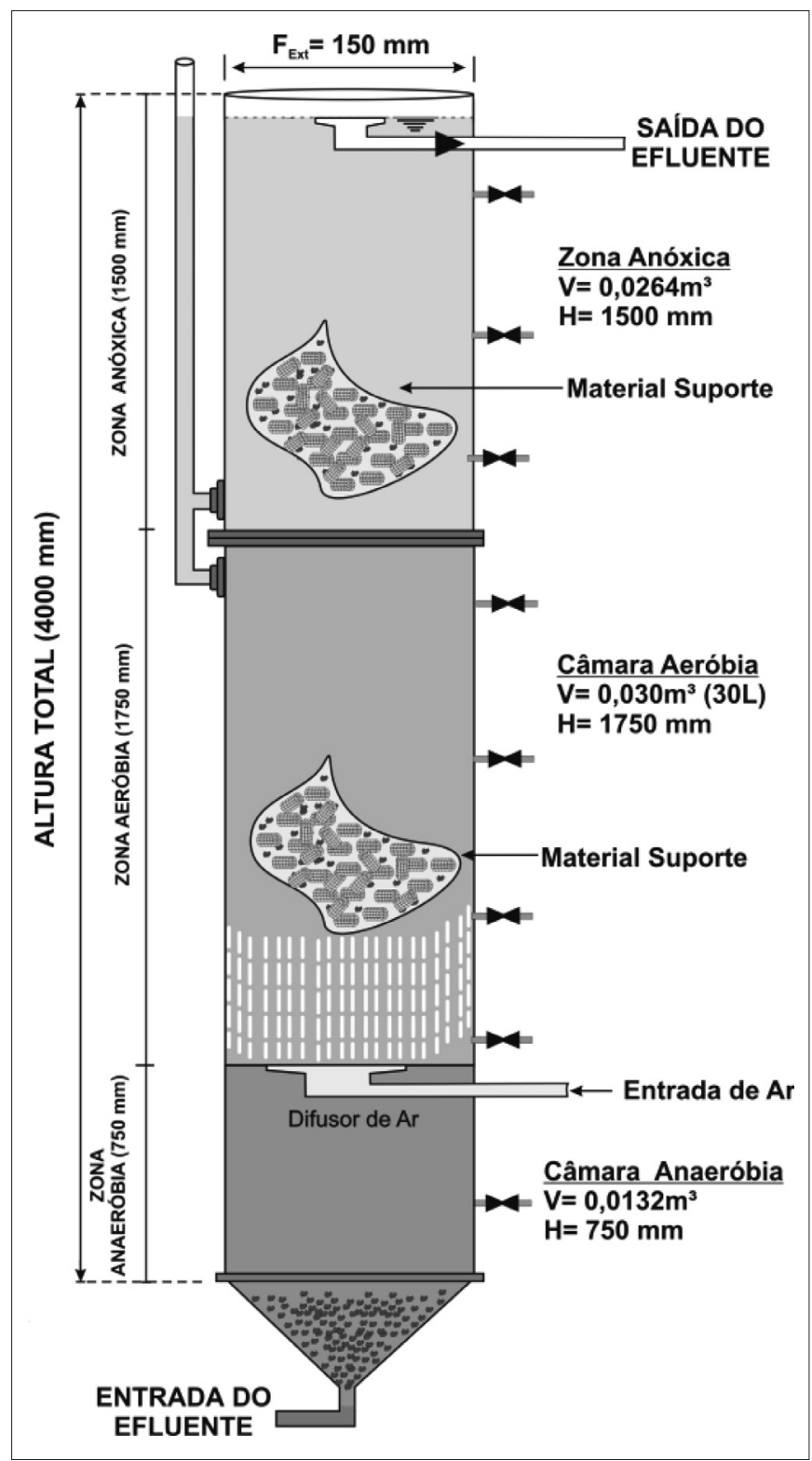

Figura 1 - Esquema simplificado de biofiltro aerado submerso multiestágio. 

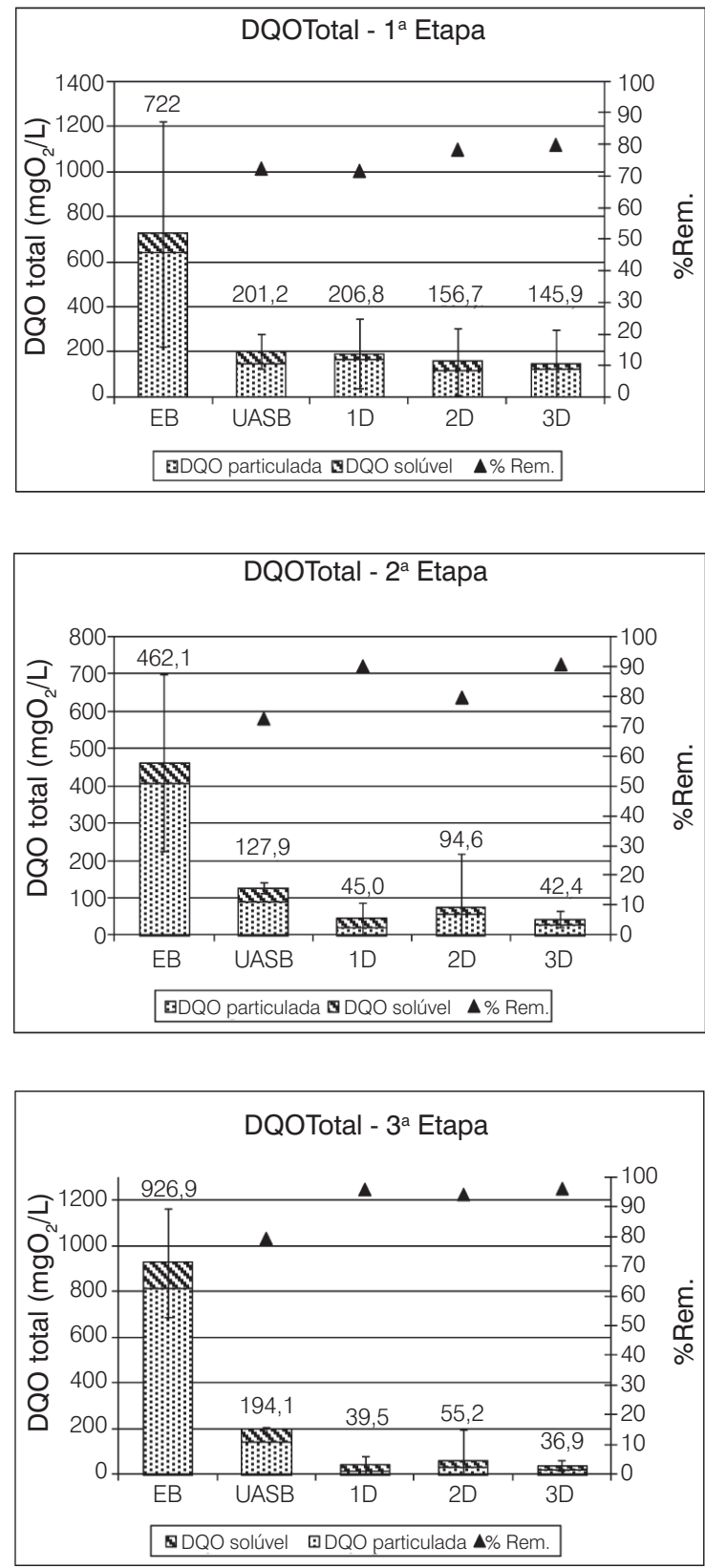

Figura 2 - Valores de DQO total e decantada para as três etapas avaliadas.

Ainda assim, as eficiências totais de remoção (em conjunto com o reator UASB, conforme Tabela 4) foram positivas nessa etapa devido ao bom desempenho do reator UASB.

Em termos de DQO decantada, os BAS apresentaram boas eficiências de remoção, obtendo concentrações inferiores a $50 \mathrm{mgO}_{2} \cdot \mathrm{L}^{-1}$ no primeiro período experimental.

A segunda etapa, configurada pelo aumento do TDH de 4,1 horas para 8,2 horas na câmara aeróbia, coincidiu com a implantação de uma rotina de remoção de lodo da câmara anóxica. Tal rotina apresentou resultados positivos, permitindo aos BAS 1 e 3 obterem concentrações de DQO total inferiores a $50 \mathrm{mgO}_{2}$. L- no efluente final.
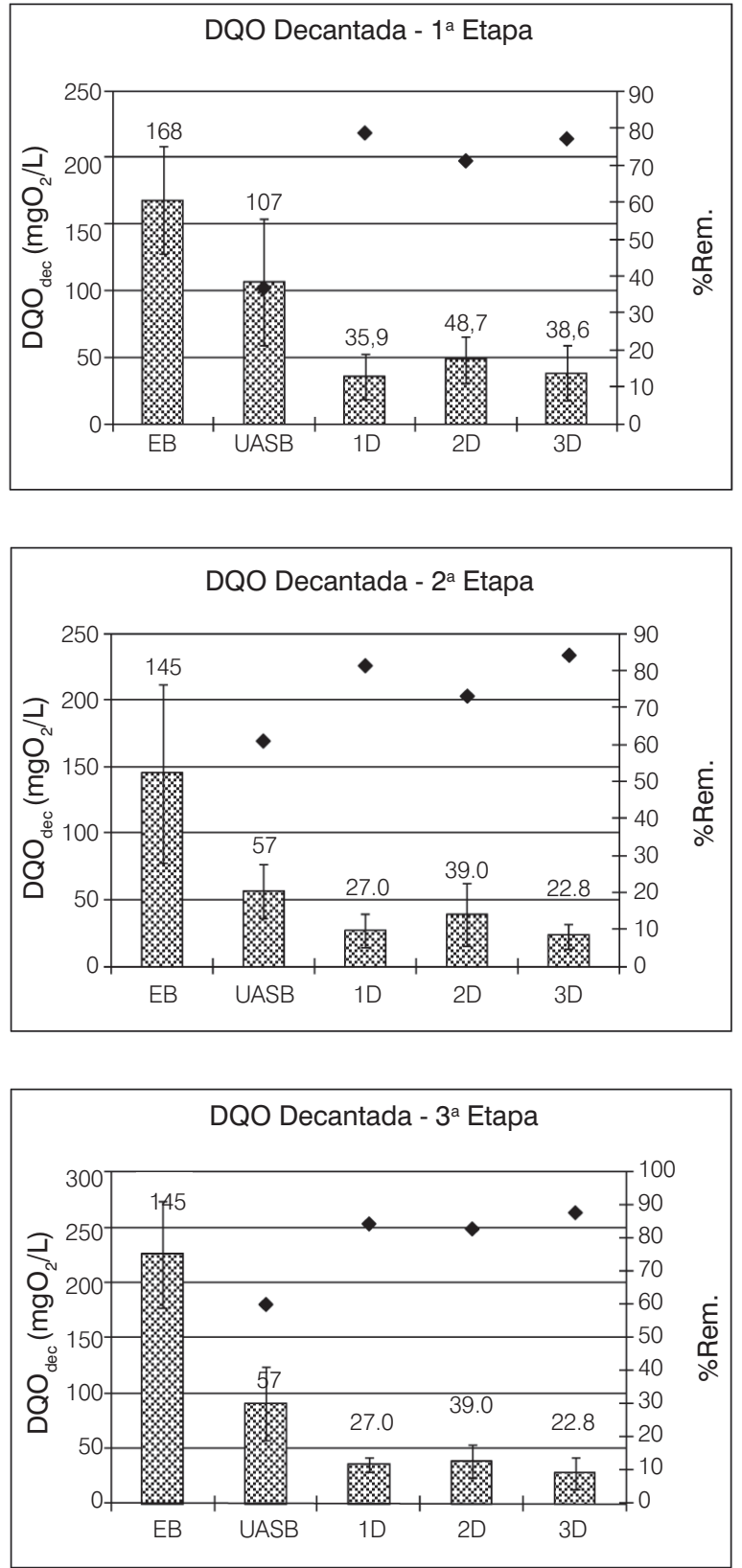

Pôde-se, por meio dessa análise, constatar que a câmara anóxica atuou de maneira eficiente na sedimentação da biomassa suspensa nos interstícios do material-suporte dos BAS. O BAS 2 continuou a apresentar eventuais perdas de SS, resultando em concentrações efluentes de DQO total superiores às dos outros biofiltros.

A terceira etapa, na qual o TDH foi elevado de 8,2 horas para 12,3 horas, não propiciou ganhos significativos em termos de eficiência de remoção total para os BAS 1 e 3. O BAS 2 apresentou eficiência de $71,5 \%$, sendo superior às verificadas nas etapas anteriores (etapa 1 e 2) e associada à melhora das características de sedimentação da biomassa intersticial desse BAS. 
Tabela 3 - Valores de DQO afluente (EB) e efluente ao reator UASB

\begin{tabular}{|c|c|c|c|c|c|c|c|}
\hline \multirow{3}{*}{ Etapa } & \multirow{3}{*}{ Ponto } & \multicolumn{6}{|c|}{ DQO } \\
\hline & & \multicolumn{2}{|c|}{ Total } & \multicolumn{2}{|c|}{ Decantada } & \multicolumn{2}{|c|}{ Solúvel } \\
\hline & & Média* & DP & Média & DP & Média & DP \\
\hline \multirow{2}{*}{$1 \underline{a}$} & EB & 722 & 500,5 & $168,1(23,3 \%)$ & 40,0 & $83,6(11,6 \%)$ & 15,4 \\
\hline & UASB & 201,2 & 76,7 & 106,6 & 47,6 & 54,6 & 44,2 \\
\hline \multirow{2}{*}{$2^{\mathrm{a}}$} & EB & 462 & 237,2 & $144,7(31,3 \%)$ & 66,7 & $54,0(11,7 \%)$ & 42,3 \\
\hline & UASB & 127,9 & 14,9 & 56,7 & 20,3 & 38,0 & 42,3 \\
\hline \multirow{2}{*}{$3^{\mathrm{a}}$} & EB & 927 & 396,9 & $225,8(24,3 \%)$ & 47,8 & $118,8(12,8 \%)$ & 81,8 \\
\hline & UASB & 194,1 & 88,5 & 90,5 & 33,6 & 56,2 & $81, \varepsilon$ \\
\hline
\end{tabular}

DP: desvio padrão; * $\mathrm{Em} \mathrm{mgO}_{2} \cdot \mathrm{L}^{-1}$.

Tabela 4 - Frações de DQO e eficiências de remoção com relação ao reator UASB e reator UASB + BAS

\begin{tabular}{|c|c|c|c|c|c|c|c|c|c|c|c|}
\hline \multirow[b]{2}{*}{ Etapa } & \multirow[b]{2}{*}{ Biofiltro } & \multirow[b]{2}{*}{$\mathrm{n}$} & \multicolumn{3}{|c|}{ DQO solúvel } & \multicolumn{3}{|c|}{ DQO decantada } & \multicolumn{3}{|c|}{ DQO Total } \\
\hline & & & $\mathrm{C}_{\text {efl }}{ }^{*}$ & $\begin{array}{c}\text { \% Eficiência } \\
\text { BAS }^{\star *}\end{array}$ & $\begin{array}{l}\text { \% Eficiência } \\
\text { total }^{* \star *}\end{array}$ & $\mathrm{C}_{\text {efl }}{ }^{*}$ & $\begin{array}{c}\text { \% Eficiência } \\
\text { BAS }^{* *}\end{array}$ & $\begin{array}{l}\text { \% Eficiência } \\
\text { total }^{* \star *}\end{array}$ & $\mathrm{C}_{\text {eff }}{ }^{*}$ & $\begin{array}{c}\text { \% Eficiência } \\
\text { BAS }^{* *}\end{array}$ & $\begin{array}{l}\text { \% Eficiência } \\
\text { total }^{* \star *}\end{array}$ \\
\hline \multirow{3}{*}{$1 \underline{a}$} & BAS 1 & 7 & 28,1 & 49 & 66 & 35,9 & 66 & 79 & 206,8 & $-2,8$ & 71,4 \\
\hline & BAS 2 & 7 & 43,9 & 20 & 48 & 48,7 & 54 & 71 & 157,4 & 21,8 & 78,2 \\
\hline & BAS 3 & 7 & 26,3 & 52 & 69 & 38,6 & 64 & 77 & 145,9 & 27,5 & 79,8 \\
\hline \multirow{3}{*}{$2^{\mathrm{a}}$} & BAS 1 & 7 & 23,3 & 39 & 57 & 27,0 & 75 & 84 & 45,0 & 65,0 & 90,0 \\
\hline & BAS 2 & 7 & 19,8 & 48 & 63 & 57,3 & 46 & 66 & 94,6 & 26,0 & 80,0 \\
\hline & BAS 3 & 7 & 13,1 & 65 & 76 & 22,8 & 79 & 86 & 42,4 & 67,0 & 91,0 \\
\hline \multirow{3}{*}{$3^{\mathrm{a}}$} & BAS 1 & 7 & 25,5 & 55 & 79 & 35,2 & 67 & 79 & 39,5 & 80,0 & 96,0 \\
\hline & BAS 2 & 7 & 26,1 & 54 & 78 & 38,7 & 64 & 77 & 55,2 & 72,0 & 94,0 \\
\hline & BAS 3 & 7 & 22,4 & 60 & 81 & 27,6 & 74 & 84 & 36,9 & 81,0 & 96,0 \\
\hline
\end{tabular}

${ }^{*}$ mg. L $^{-1}$; ** eficiência em relação ao reator UASB; ***eficiência total (UASB+BAS)

O melhor desempenho de remoção de DQO total nos BAS 1 e 3 em comparação ao BAS 2 pode estar associado à maior área superficial e ao índice de vazios dos materiais-suporte empregados nos BAS 1 e 3 (75 e 95\% para tampas e gargalos de garrafa PET e anéis Pall, respectivamente), propiciando uma maior área de biofilme e melhor distribuição da alimentação bem como uma menor velocidade ascensional, reduzindo o arraste do lodo. Essas características interferiram na capacidade de retenção de sólidos na câmara anóxica dos BAS, a qual serviu como sedimentador da biomassa suspensa originada da câmara aeróbia. Nesse caso, a menor eficiência de DQO total pelo BAS 2 foi provavelmente associada ao material-suporte.

Em termos de DQO decantada, não foram verificadas diferenças estatísticas entre os valores nas três etapas avaliadas, obtendo-se, já a partir da primeira etapa, concentrações médias de $50 \mathrm{mgO}_{2} \cdot \mathrm{L}^{-1}$. Verifica-se, dessa forma, que variações no TDH não influenciaram de forma determinante a eficiência dos sistemas relativamente a DQO.

A análise dos dados apresentados na Figura 2 em termos de concentrações efluentes de DQO decantada e os padrões exigidos pela Resolução CONSEMA n. ${ }^{\circ}$ 128/06 permitem observar que os mesmos são atendidos a partir da primeira etapa, sugerindo que os BAS poderiam operar com um TDH menor do que os testados para a obtenção de resultados satisfatórios em termos de remoção de DQO total.
À exceção da primeira etapa, na qual houve interferência dos SS nos resultados, as eficiências de remoção de DQO total dos sistemas UASB+BAS 1 e BAS 3 foram iguais ou superiores a 90\%. Tais valores corroboram os obtidos por Hirakawa et al. (2002) na operação de um sistema UASB+BAS, os quais situaram-se entre 80 e $90 \%$.

Em termos de DQO total, um comparativo entre os dados obtidos pelos BAS e a legislação ambiental vigente no Estado do Rio Grande do Sul (Resolução CONSEMA n. ${ }^{\circ}$ 128/2006) aponta para o atendimento dos padrões de emissão a partir da segunda etapa do experimento, já que essa legislação estipula para a pior situação (vazão superior a $10.000 \mathrm{~m}^{3} \cdot \mathrm{d}^{-1}$ ) um valor limite de $150 \mathrm{mgO}_{2} \cdot \mathrm{L}^{-1}$ para DQO total. Em termos de DQO decantada, os sistemas de BAS atenderam os padrões de lançamento da mesma legislação nas três etapas analisadas.

Se considerados os padrões de lançamento da NBR 13.969/97 (sobre sistemas de tratamento locais complementares para efluentes de tanques sépticos), mais restritiva, o máximo permitido para lançamento de DQO é de $75 \mathrm{mgO}_{2} \cdot \mathrm{L}^{-1}$. Nesse caso, os BAS 1 e 3 atenderiam os padrões de lançamento também a partir da segunda etapa, considerando-se a DQO total. Todos os BAS atenderiam aos padrões de emissão após sedimentação (DQO decantada).

Os bons resultados obtidos pelos BAS estão possivelmente relacionados ao baixo conteúdo de matéria orgânica biodegradável no efluente após tratamento pelo reator UASB, bem como às elevadas eficiências inerentes a sistemas aeróbios na remoção de matéria orgânica. 


\section{Remoção de carga orgânica volumétrica}

Na Figura 3 compara-se a carga de DQO total aplicada à COV removida nas diferentes etapas do experimento. Observa-se que não há sobrecarga em nenhum dos BAS testados, com a aplicação de cargas próximas a $5 \mathrm{kgDQO} / \mathrm{m}^{3}$.d, já que a remoção de DQO total é diretamente proporcional à carga aplicada aos sistemas. Tem-se, então, que a remoção de DQO total para essa faixa de aplicação de cargas pode ser ajustada por uma reação de primeira ordem.

A COV aplicada na câmara aeróbia dos BAS variou de 1,31 a $3,81 \mathrm{kgDQO} \cdot \mathrm{m}^{3} \cdot \mathrm{d}^{-1}$ para a primeira etapa, 0,64 a $1,1 \mathrm{kgDQO} \cdot \mathrm{m}^{3} \cdot \mathrm{d}^{-1}$ para a segunda e de 0,45 a $1,6 \mathrm{kgDQO} \cdot \mathrm{m}^{3} \cdot \mathrm{d}^{-1}$ para a terceira etapa. Todas as taxas foram relacionadas ao volume da câmara aeróbia. A seguir são apresentadas as equações de ajuste para os BAS:

\section{BAS 1}

$y=0,86 x-0,15 \quad R 2=0,97$

Equação 1

BAS 2

$y-0,89 x-0,25 \quad R 2=0,93$

Equação 2

BAS 3

$y=1,0 x-0,3 \quad R 2=0,97$ onde:

y: carga removida, $g\left(D_{Q} O_{t}\right) \cdot m^{3} \cdot d^{-1}$;

$\mathrm{x}$ : carga aplicada, em g (DQO $) \cdot \mathrm{m}^{3} \cdot \mathrm{d}^{-1}$.

O comparativo dos valores obtidos e o estabelecido como padrão mais restritivo pela Resolução CONSEMA n. ${ }^{\circ}$ 128/06 (DBO 540 $\mathrm{mgO}_{2} \cdot \mathrm{L}^{-1}$ para $\left.\mathrm{Q}>10.000 \mathrm{~m}^{3} \cdot \mathrm{d}^{-1}\right)$, aponta para o pleno atendimento pelos BAS.

\section{$\mathrm{DBO}_{5}$ efluente e relação $\mathrm{DBO}_{5} / \mathrm{DQO}$}

Os valores de $\mathrm{DBO}_{5}$ para o efluente dos BAS são apresentados na Figura 4A. A análise dos dados aponta para baixas concentrações efluentes de $\mathrm{DBO}_{5}$ para os BAS 1 e 3 , os quais apresentaram valores inferiores a $10 \mathrm{mg} . \mathrm{L}^{-1}$ no efluente final ao longo de todo o experimento. O BAS 2, por sua vez, apresentou valores médios de concentração entre 20 e $30 \mathrm{mgO}_{2} \cdot \mathrm{L}^{-1}$.

Os BAS 1 e 3 apresentaram relações $\mathrm{DBO}_{5} / \mathrm{DQO}_{1}$ médias de 0,11 e 0,28 , respectivamente, apontando para um efluente final com reduzida parcela biodegradável. Por outro lado, o BAS 2 apresentou um relação DBO5/DQO média de 0,52, sendo esse valor associado à interferência de SS presente no efluente final desse biofiltro. A Figura

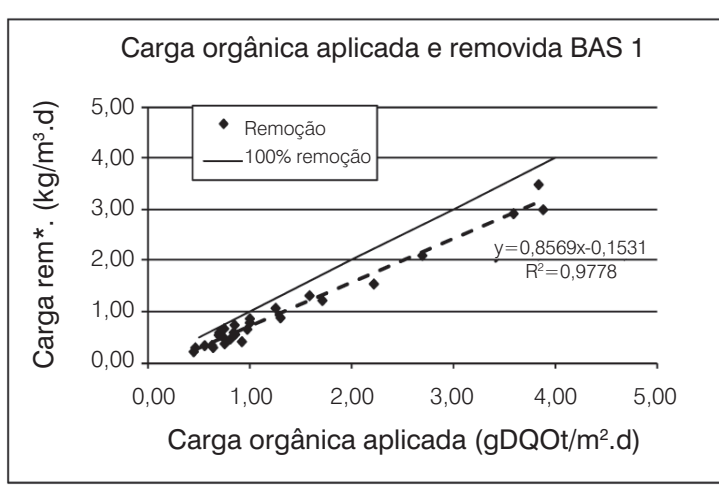

(A)

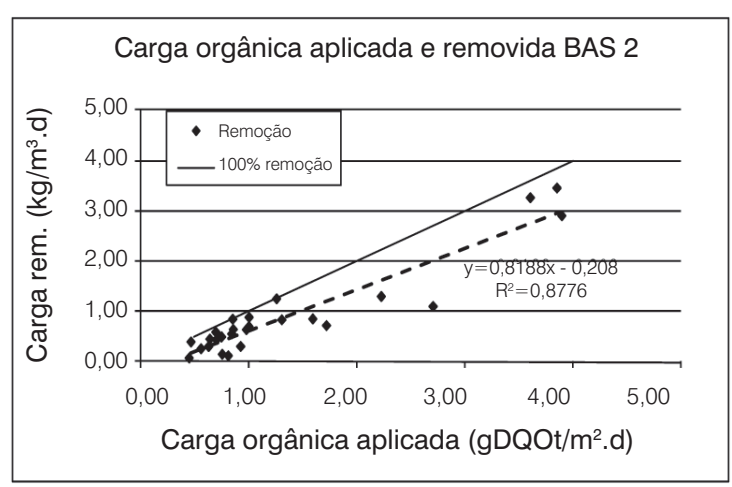

(B)

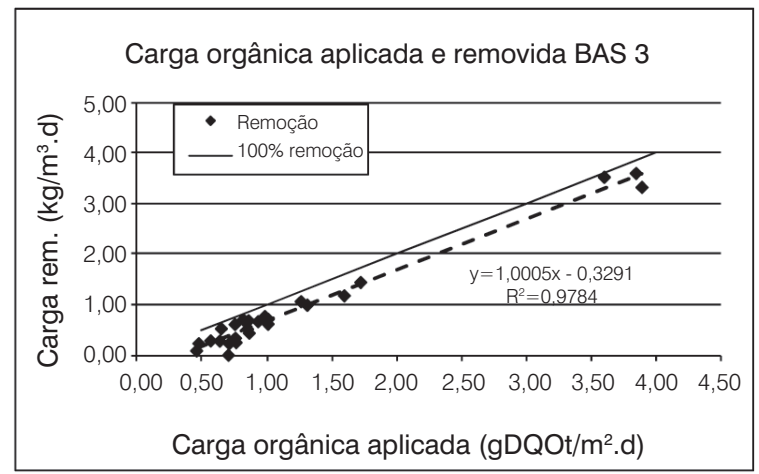

(C)

Figura 3 - Cargas orgânicas aplicadas e removidas para os BAS 1,2 e 3. 


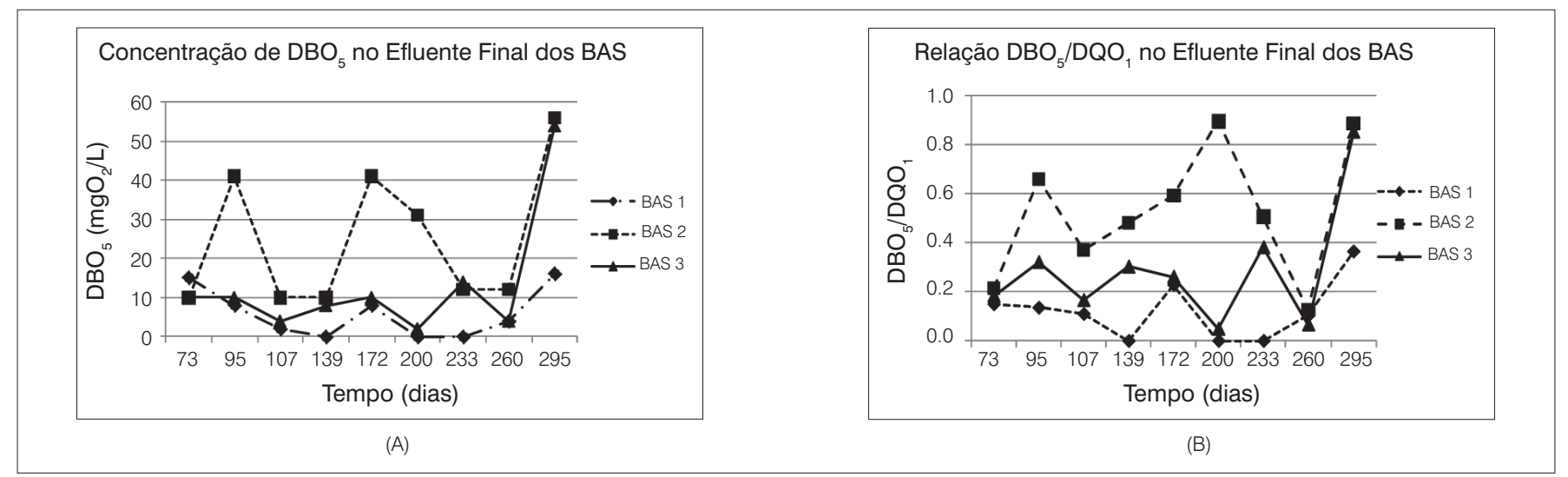

Figura 4 - (A) Valores de $\mathrm{DBO}_{5}$ e (B) relação $\mathrm{DBO}_{5} / \mathrm{DQO}_{\mathrm{t}}$ para 0 efluente dos $\mathrm{BAS}$.

4B apresenta a variação dessa relação ao longo de todo o período experimental para os três BAS avaliados.

O efluente bruto apresentou relação $\mathrm{DBO}_{5} / \mathrm{DQO}$ de aproximadamente 0,58 , valor este pouco superior ao intervalo de 0,4 a 0,5 normalmente citado na literatura para efluente sanitário. O efluente do reator UASB, por sua vez, apresentou relação média de 0,61; sendo o aumento da relação para o reator UASB associado à solubilização da matéria orgânica particulada digerida pelo reator.

\section{Remoção do excesso de lodo (biossólidos)}

A remoção de lodo dos BAS foi realizada em dois pontos: na câmara anaeróbia e na base da câmara anóxica. A remoção de lodo na câmara anaeróbia foi realizada com o objetivo de retirar sólidos acumulados provenientes do reator UASB. A remoção de lodo da câmara anóxica visou à melhora da qualidade do efluente final, já que essa câmara teve função adicional de sedimentação dos sólidos perdidos pela câmara aeróbia.

O volume de lodo removido da câmara anaeróbia foi de 12L por semana, sendo essa alíquota praticamente equivalente ao total da câmara anaeróbia. O mesmo procedimento foi adotado para retirada de lodo da câmara anóxica, com remoção total do volume útil desta $(\mathrm{V}=26,4 \mathrm{~L})$. A retirada de lodo tanto da câmara anóxica quanto da anaeróbia ocorreu somente a partir da segunda fase do experimento, momento no qual se observou uma crescente concentração de sólidos na câmara anaeróbia e no efluente final dos BAS.

\section{Taxa de aplicação superficial e efeito na remoção de SS}

Os BAS foram operados a uma taxa de aplicação superficial (TAS) de $23 \mathrm{~m}^{3} \cdot \mathrm{m}^{2} \cdot \mathrm{d}^{-1}$ ao longo da primeira etapa - taxa próxima à comumente verificada em BAS (BARBOSA, 2006). A avaliação da influência da TAS sobre a remoção de SS pelos BAS na primeira etapa sofreu interferência pela perda de sólidos acumulados na câmara anóxica dos biofiltros.
Tabela 5 - Concentrações de SS para o afluente e efluente do reator UASB

\begin{tabular}{lcccc}
\multirow{2}{*}{ Etapa } & & \multicolumn{2}{c}{ Sólidos suspensos $\left(\mathrm{mg} \cdot \mathrm{L}^{-1}\right)$} & Eficiência de remoção \\
\cline { 3 - 5 } & & Média & DP & $\%$ \\
\hline \multirow{2}{*}{1} & EB & 591,6 & 630,8 & - \\
\cline { 3 - 5 } 2 & UASB & 96,4 & 54,9 & 84 \\
\hline \multirow{2}{*}{3} & EB & 943,7 & 893,1 & - \\
\hline \multirow{2}{*}{3} & UASB & 214,0 & 97,2 & 77 \\
& EB & 813,1 & 567,3 & - \\
\hline
\end{tabular}

DP: desvio padrão.

A Tabela 5 apresenta os dados de remoção de SS pelo reator UASB relativamente ao efluente bruto afluente. Nota-se elevada concentração de SS no efluente bruto afluente à estação experimental, especialmente nas etapas 2 e 3 . A mesma tabela mostra que o reator UASB desempenhou seu papel na remoção de SS afluentes à estação, com eficiências acima de 70\% nas três etapas analisadas.

Os valores de remoção total de SS na primeira etapa foram relativamente baixos, conforme Tabela 6 , pois a operação da primeira etapa foi realizada sem a remoção de lodo dos biofiltros, justificando as baixas eficiências de remoção obtidas por estes em relação ao reator UASB (Tabela 6).

A redução da TAS de 23 para $12 \mathrm{~m}^{3} \cdot \mathrm{m}^{2} \cdot \mathrm{d}^{-1}$ na segunda etapa do experimento e o início da rotina de remoção de sólidos nos BAS ao mesmo tempo impossibilitou a interpretação clara do efeito da redução da TAS sobre a eficiência de remoção de SS pelo BAS, particularmente pela câmara anóxica. Porém, as eficiências totais de remoção melhoraram sensivelmente, variando de 87 (BAS 2) a 97\% (BAS 1 e 3), (Tabela 6). As concentrações médias efluentes de SS na saída dos BAS 1, 2 e 3 (Tabela 6) demonstram uma possível interferência do material-suporte na eficiência de remoção de sólidos pelos BAS, já que, nesse período, não houve qualquer mudança ou problema operacional que justificasse as diferenças de valores entre os BAS 1 e 3 e o BAS 2, o qual apresentou o pior desempenho (Figura 5).

A redução da TAS de 12 para $8 \mathrm{~m}^{3} \cdot \mathrm{m}^{2} \cdot \mathrm{h}^{-1}$ na terceira etapa não interferiu significativamente na remoção de SS dos BAS. Dessa forma, 
Tabela 6 - Concentrações de SS e eficiências de remoção para os sistemas UASB+BAS

\begin{tabular}{|c|c|c|c|c|c|}
\hline \multirow{2}{*}{ Etapa } & & \multicolumn{2}{|c|}{ Sólidos suspensos (mgSS.L-1) } & \multicolumn{2}{|c|}{ Eficiência de remoção (\%) } \\
\hline & & Média & DP & BAS* & Total ${ }^{\star *}$ \\
\hline \multirow[t]{3}{*}{1} & BAS 1 & 403,1 & 634,9 & -318 & 32 \\
\hline & BAS 2 & 128,7 & 82,0 & -33 & 78 \\
\hline & BAS 3 & 67,0 & 72,1 & 31 & 89 \\
\hline \multirow[t]{3}{*}{2} & BAS 1 & 25,3 & 12,7 & 88 & 97 \\
\hline & BAS 2 & 120,7 & 111,9 & 44 & 87 \\
\hline & BAS 3 & 85,1 & 87,2 & 60 & 91 \\
\hline \multirow[t]{3}{*}{3} & BAS 1 & 17,3 & 12,7 & 81 & 98 \\
\hline & BAS 2 & 48,7 & 41,0 & 48 & 94 \\
\hline & BAS 3 & 18,7 & 22,9 & 80 & 98 \\
\hline
\end{tabular}

* Em relação ao reator UASB; ** sistemas UASB+BAS; DP: desvio padrão; BAS: biofiltro aeróbio submerso.
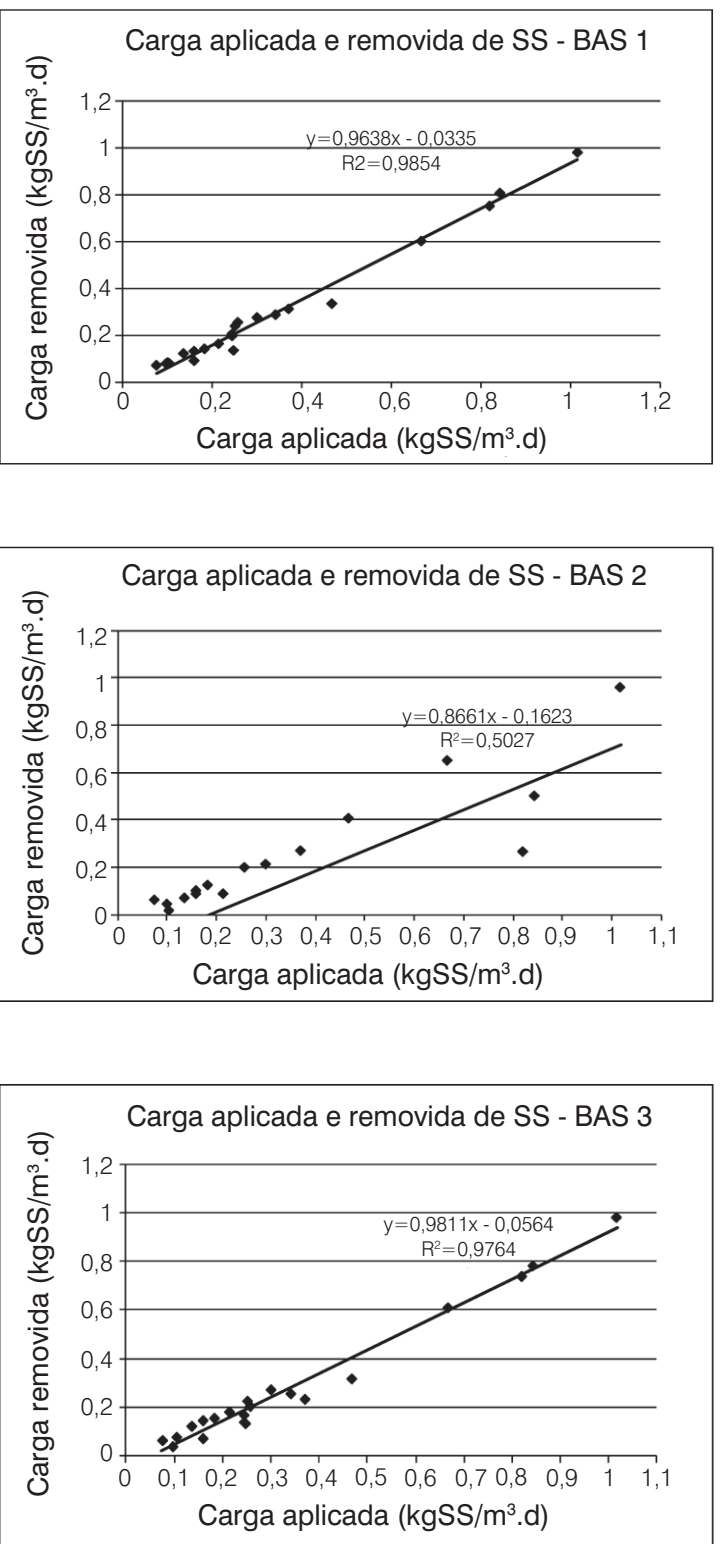
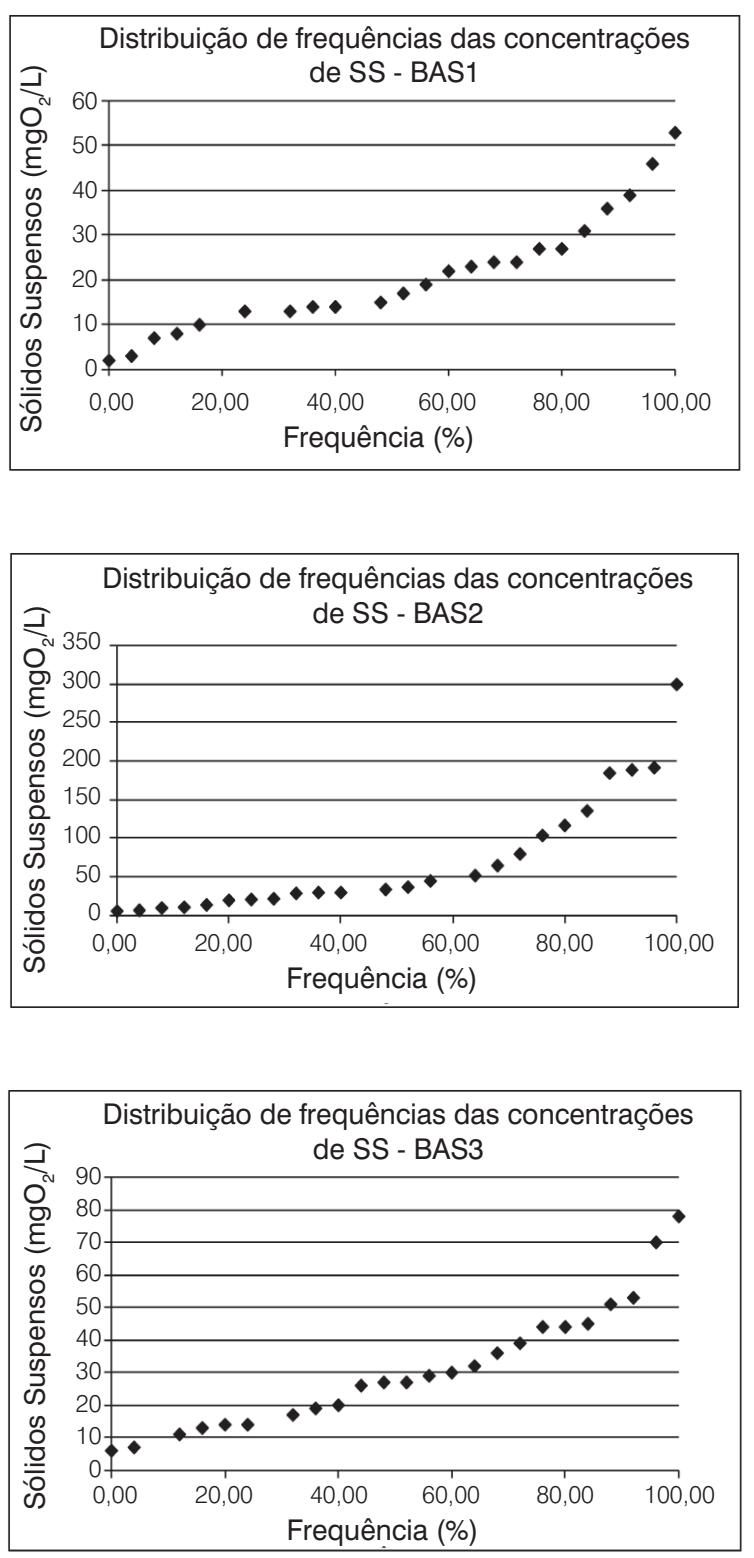

Figura 5 - Comportamento do parâmetro DQO para os BAS na 3a etapa. 


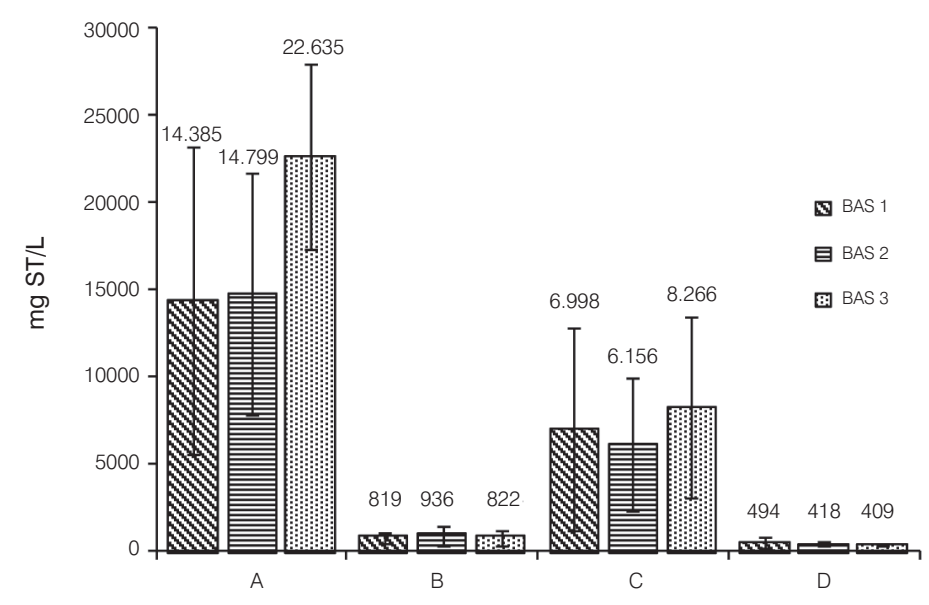

Figura 6 - Perfil de sólidos para os BAS ao longo de todo o período experimental. Ponto A: câmara anaeróbia; B: câmara aeróbia; C: base da câmara anóxica; D: saída do BAS.

as elevadas eficiências de remoção de SS pelos BAS parecem estar associadas principalmente à rotina de remoção de lodos do que a TAS empregada nos BAS.

\section{Perfil de sólidos totais}

O perfil de concentrações médias de sólidos totais observados para os BAS é apresentado na Figura 6, na qual, destacam-se grandes concentrações de ST para os pontos A (câmara anaeróbia) e C (entrada da câmara anóxica) para todos os BAS.

Para o ponto A, o comportamento é justificado pelo efeito de acúmulo de sólidos perdidos pelo reator UASB, bem como de biomassa desprendida do material-suporte dos próprios BAS. Os sólidos retidos nessa câmara eram removidos semanalmente (12L).

As elevadas concentrações de lodo na base da câmara anóxica provavelmente ocorreram pela baixa turbulência nela existente, propiciando condições para a sedimentação de biomassa no local. O lodo dessa câmara era removido a cada 15 dias, em virtude da baixa produção de sólidos pelos biofiltros, sendo a câmara totalmente esvaziada (26L) a cada limpeza. O ponto D representa a saída dos BAS, na qual é possível observar valores de ST bem inferiores aos verificados no ponto C.

\section{Conclusões}

O emprego de BAS multiestágio no pós-tratamento de reatores UASB apresentou ótimo desempenho na remoção de DQO total e SS, alcançando em ambos os parâmetros eficiências totais (UASB+BAS) superiores a $85 \%$ nas três etapas experimentais avaliadas. O efluente final caracterizou-se por um elevado grau de estabilização, sendo verificados valores de $\mathrm{DBO}_{5}$ inferiores a $10 \mathrm{mgO}_{2} / \mathrm{L}$ para os BAS 1 e 3. O BAS 2, tendo como material- suporte a brita n. ${ }^{\circ} 4$, apresentou valores inferiores de eficiência em temos de $\mathrm{DQO}$ e $\mathrm{DBO}_{5}$ devido à maior perda de SS. Podese afirmar, com base nos resultados obtidos, que a conformação empregada de BAS, quando utilizados materiais com elevados índices de vazios (tampas e gargalos de garrafas PET e anéis Pall), possibilita elevadas remoções de SS, tornando desnecessário uso o decantador secundário.

Em termos operacionais, a remoção periódica de lodo da câmara anaeróbia e da câmara anóxica dos BAS contribuiu de forma significativa na eficiência de remoção de $\mathrm{DQO}$ e $\mathrm{DBO}_{5}$, associadas à redução da interferência de perda de sólidos no efluente final.

Os sistemas UASB+BAS apresentaram, especificamente para os materiais-suporte tampas e gargalos de garrafa PET e anéis Pall, elevada estabilidade nos valores dos parâmetros para o efluente final, independentemente da variabilidade do efluente bruto. A operação conjunta do reator UASB+BAS permitiu contrabalançar perdas momentâneas de eficiência de qualquer das unidades, minimizando ao máximo a interferência na eficiência global do processo.

Dessa forma, pode-se concluir que a combinação de reator UASB seguido de BAS multiestágio mostrou ser uma excelente alternativa para o tratamento de efluente sanitário, permitindo a obtenção de um efluente dentro dos padrões ambientais legais de remoção de matéria orgânica e SS.

\section{Agradecimentos}

Os autores agradecem ao Departamento Municipal de Água e Esgoto (DMAE) de Porto Alegre, pela disponibilização do espaço; ao Conselho Nacional de Desenvolvimento Científico e Tecnológico (CNPq), pelo financiamento da pesquisa; e ao Instituto de Pesquisas Hidráulicas da UFRGS pela oportunidade acadêmica. 


\section{Referências}

AISSE, M.M.; SOBRINHO, P.A. Avaliação do sistema reator UASB e filtro biológico aerado submerso para o tratamento de esgoto sanitário. Póstratamento de efluentes de reatores anaeróbios. In: Chernicharo, C.A.L. (coord.). Coletânea de Trabalhos Técnicos. Belo Horizonte: Projeto PROSAB, 2000. p.119-134.

APHA; AWWA; WEF. Stardard methods for the examination of water and wastewater. 21. ed. Washington, D.C.: American Public Health Association, 2005.

ASSOCIAÇÃO BRASILEIRA DE NORMAS TÉCNICAS (ABNT). NBR13.969 - Tanques sépticos - Unidades de tratamento complementar e disposição final dos efluentes líquidos - Projeto, construção e operação. Rio de Janeiro: ABNT, 1997.

BARBOSA, S.A. Avaliação de biofiltro aerado submerso no pós-tratamento de efluente de tanque séptico. 2006. 207f. Dissertação (Mestrado em Engenharia de Recursos Hídricos e Ambiental). Pós-Graduação em Engenharia de Recursos Hídricos e Ambiental, Universidade Federal do Paraná, Curitiba, 2006.

CHERNICHARO, C.A.L. Princípios do tratamento biológico de águas residuárias - Reatores anaeróbios. Belo Horizonte: Departamento de Engenharia Sanitária e Ambiental - DESA/UFMG; 1997. v. 5.

GÁLVEZ, J.M. et al. Influence of hydraulic loading and air flow rate on urban wastewater nitrogen removal with a submerged fixed-film reactor. Journal of Hazardous Materials, v. 101, p. 219-229, 2003.

GONÇALVES, R.F. et al. Pós-tratamento de efluentes de reatores anaeróbios por reatores de biofilme. In: CHERNICHARO, C.A.L. (Coord.). Pós-tratamento de efluentes de reatores anaeróbios. Belo Horizonte: Projeto PROSAB 2, 2001. p. 171-278.

GONÇALVES, R.F.; ARAÚJO, V.L.; CHERNICHARO, C.A. Tratamento secundário de esgoto doméstico sanitário através da associação em série de reatores UASB e biofiltros aerados submersos. In: CONGRESSO BRASILEIRO DE ENGENHARIA SANITÁRIA E AMBIENTAL, 19, Foz do Iguaçu, 1997. Anais, Rio de Janeiro, ABES. p. 450-61, 1997.
HE, S.B.; XUE, G.; KONG H.N. The performance of BAF using natural zeolite as filter media under conditions of low temperature and ammonium shock load. Journal of Hazardous Materials, v. 143, n. 1-2, p. 291-295, 2007

HIRAKAWA, C.; PIVELI, R.P.; SOBRINHO, P.A. Biofiltro aerado submerso aplicado ao pós-tratamento de efluente de reator UASB - estudo em escala piloto com esgoto sanitário. Revista de Engenharia Sanitária e Ambiental, v. 7, n. 1-2, p. 82-94, 2002.

LIU, Y.X. et al. Study of municipal wastewater treatment with oyster shell as biological aerated filter medium. Desalination, v. 254, p. 149-153, 2010.

MOORE, R.; QUARMBY, J.; STEPHENSON, T. The effects of media size on the performance of biological aerated filters. Water Research, v. 35 n. 10, p. 2514-2522, 2001.

QIU, L. et al. Performances and nitrification properties of biological aerated filters. Bioresource Technology, v. 101, p. 7245-7251, 2010.

RIO GRANDE DO SUL. Conselho Estadual do Meio Ambiente. Resolução n. ${ }^{128 / 2006}$. Dispõe sobre a fixação de Padrões de Emissão de Efluentes Líquidos para fontes de emissão que lancem seus efluentes em águas superficiais no Estado do Rio Grande do Sul. Porto Alegre: CONSEMA, 2006.

VIEIRA, S.M.M. Anaerobic treatment of domestic wastewater in Brazil: research and full-scale experience. Advanced Water Pollution Control, n. 5, p. 185-186, 1988.

WANG, C. et al. Development of an empirical model for domestic wastewater treatment by biological aerated filter. Process Biochemistry, v. 41, p. $778-782,2006$.

XIE, B. et al. Landfill leachate pollutant removal performance of a novel biofilter packed with mixture medium. Bioresource Technology, v. 101, n. 20, p. 7754-7760, 2010. 